S E C C IÓ N
A B I E R T A

\title{
UNA APROXIMACIÓN BIOGRÁFICA a don Fermín José Fuero: obispo de Chiapas
}

\author{
David Martínez Vellisca
}

Resumen: A partir de un minucioso trabajo de archivo, y con el propósito de contribuir a salvaguardar la memoria histórica de Chiapas, en este texto se explora la vida peninsular de quien fuera obispo de Chiapa y Soconusco, don Fermín José Fuero Gómez, natural de la villa de Cañizares (Cuenca), quien fue preconizado el 18 de julio de 1795 y consagrado en Guatemala el 11 de septiembre de 1796.

Palabras clave: Fuero, Chiapas, memoria histórica, educación eclesiástica, clero.

David Martínez Vellisca, doctor en Antropología, Universidad de Horche, Guadalajara, España, correo electrónico: archivohorche@hotmail.com.
Abstract: From a meticulous archive's work, and in order to contribute to safeguard the historical memory of Chiapas, in this text the Spanish life's period of the outsider bishop of Chiapa and Soconusco, Don Fermin José Fuero Gómez, native from villa de Cañizares (Cuenca), who was praised on July 18th, 1795, and consecrated in Guatemala on September 11th, 1796, is explored.

Key words: Fuero, Chiapas, historical memory, ecclesiastical education, clergy.

\section{Escribir la historia de Chiapas}

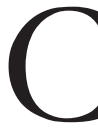
on estas palabras se describe un proyecto cuyo objetivo es recuperar y salvaguardar la documentación de los Archivos de Chiapas en sus diversas tipologías, para que la memoria histórica y más reciente no sea olvidada. ${ }^{1}$ Con asiduidad, al tratar de reescribir un asunto, un acontecimiento o la vida de un personaje, o simplemente al escribir por primera vez lo que fue, nos damos cuenta de que la historiografía se ha comportado de forma desigual, teniendo que tomar voz, empuje y reclamar el puesto que se merece.

Las épocas históricas, cualquiera que sea su localización geográfica, y cada una envuelta en sus propias leyendas, vicios y virtudes, han conferido momentos más o menos destacados que encierran otros más pequeños, repletos de personajes quienes, 
desde un escalón humilde pero significativo, contribuyeron a crearlas. Este es el caso del que llegó a ser Obispo de Chiapas, Don Fermín José Fuero Gómez, natural de la villa de Cañizares (Cuenca), quien educado y arropado siempre por su familia, tras su formación religiosa en varias instituciones, se trasladó a México para continuar la carrera eclesiástica, llegando a ser calificado como un "varón de grandes virtudes" de quien "sobresalían la humanidad, el desinterés, la justicia, la liberalidad, la religión y la fortaleza" (Flores Ruiz, 1978: 109). ${ }^{2}$

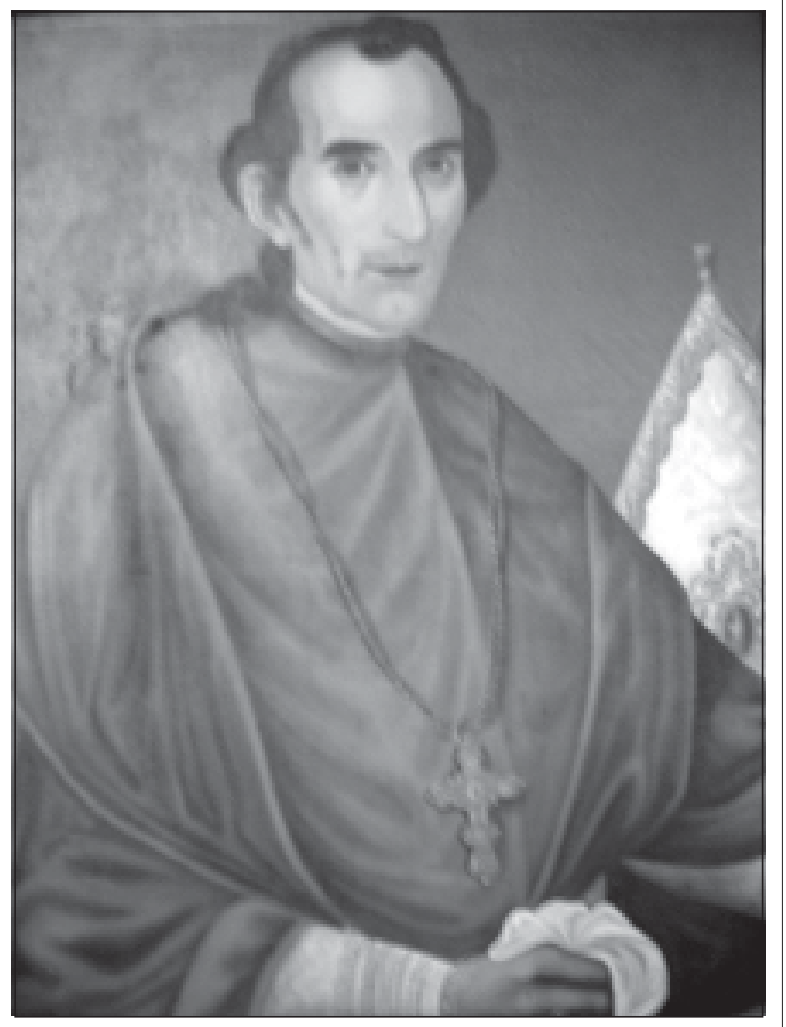

Don Fermín José Fuero, obispo de Chiapa y Soconusco (1795-1800), Archivo Histórico Diocesano de San Cristóbal de Las Casas, Chiapas. Foto: Sergio Nicolás Gutiérrez Cruz.

\section{Aclaración de identidades}

Como se ha señalado, la historiografía no siempre ha sido justa, y por eso tendrá que llegar el momento oportuno para la aclaración, primero de las identidades, y de los datos biográficos más tarde. Ha resultado que el primer apellido de Fermín José, al igual que a otros familiares, le ha valido como signo de distinción: Fuero. Pero la falta de información y el empleo de datos inexactos han colaborado a mantener errores gravísimos como el siguiente: "Pasó después a América acompañando a su tío don Francisco Fabián y Fuero, obispo de Puebla de los Ángeles y, más tarde, arzobispo de Valencia" (Priego y Silva, 2002: 143). ${ }^{3}$

Así, con el apellido Fuero, vamos a encontrar un elevado número de personajes que participaron de la carrera eclesiástica durante el siglo XVIII y hasta el XIX, con casi total preponderancia en la actual provincia de Cuenca. De todos ellos, los cuatro siguientes han escrito, a su modo y en menor o mayor medida, la historia de México durante el siglo XVIII:

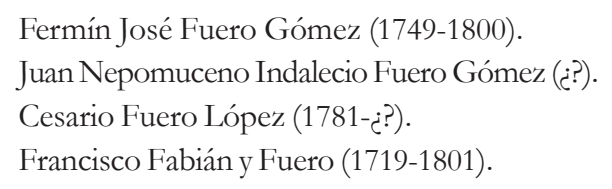

De Juan Nepomuceno Indalecio únicamente puedo señalar que fue hermano del Señor Obispo y que ocupó varios cargos eclesiásticos, como el de Arcediano, Provisor y Vicario General en Chiapas, así como candidato a Cortes (Dym, 2000: 29). ${ }^{4}$ De Cesario ${ }^{5}$ los datos son poco significativos en cuanto a su estancia en las "Indias", ya que se dice en unas notas que "dejó la beca cumplido el curso del año de 1796 y paso [sic] a la Indias con su Hermano Obispo en aquellas partes y no tuvo efecto por las Guerras con la Inglaterra", añadiéndose que más tarde ocupó los curatos de dos parroquias de la provincia de Cuenca. ${ }^{6}$ 
En cuanto a Francisco Fabián y Fuero, ya viene gozando de un reconocimiento en España y en México (Minguella, 1910-1913: 412). ${ }^{7}$ En la España Moderna, por haber sido Rector de la Universidad-Colegio de San Antonio de Porta Coeli (Sigüenza), Canónigo Doctoral en la Primada de Toledo, ${ }^{8}$ Arzobispo de Valencia ${ }^{9}$ y protagonista de sucesos como el enfrentamiento con el Duque de la Roca ${ }^{10}$ en su etapa novohispana, por la participación en la expulsión de la Compañía de Jesús, en la apertura de la Biblioteca Palafoxiana al pueblo, por la reforma de las monjas Calzadas y por el Concilio iv Mexicano. ${ }^{11}$

Y sobre Fermín Fuero, hay que comentar su paso por la Universidad de Alcalá de Henares, por el Seminario de San Julián de Cuenca, la aceptación de una capellanía de sangre o parentesco en su pueblo natal y el paso a México como Canónigo Doctoral en la Real Colegiata de Nuestra Señora de Guadalupe, Deán de Oaxaca y, finalmente, Obispo de Chiapas.

\section{Apuntes biográficos del obispo Etapa española}

Respecto a Fermín José, realmente nos encontramos ante la génesis, creación y recreación de su línea cronológica y biográfica, en el período que abarca su nacimiento hasta la marcha a México, con los inconvenientes que esto conlleva, tales como que la información bibliográfica y de fuentes escritas que se maneja, aunque valiosa, es indirecta, escasa o incluso inexistente en algunos aspectos. ${ }^{12}$

Para comenzar a tener una visión completa, hay que decir que en la villa de Cañizares, Obispado de Cuenca, el 7 de julio de 1749 nació y fue bautizado seis días más tarde, de la unión legítima de Vicente Fuero Martínez y Manuela Gómez Azañón, naturales y vecinos de la misma, un niño al que se le puso por nombre "Fermín José. Y fue su padrino Don Juan de Azañón, cura propio de la Parroquial de Carrascosa de la Sierra, tío del bautizado". ${ }^{13}$
Durante su juventud y primeros estudios, Fermín se encontró con un entramado familiar perfectamente organizado, establecido ya desde el inicio del XVIII o incluso antes, como ya ha quedado demostrado en la figura de su tío, D. Francisco Antonio Fuero Martínez (1723-1802), quien alcanzó varios beneficios curados, Comisario del Santo Oficio del Tribunal de Cuenca y Canónigo de su Santa Iglesia Catedral (Martínez Vellisca, 2003: 4 y ss.), ${ }^{14}$ así como en las de sus dos hermanos Jacinto y Manuel Fuero Gómez, quienes llegaron a ser Familiares del Santo Oficio del mismo Tribunal y en las de un buen número de familiares que, con el apellido Fuero, participaron de la carrera eclesiástica a lo largo de todo el siglo XVIII y comienzos del xIx: Pedro Fuero López, ${ }^{15}$ Ramón Fuero Carrascosa, Justo Fuero Gómez, Fermín Fuero Gómez, Julián Castillo Fuero, Francisco Antonio Fuero Gómez, María Isabel Juliana Fuero Gómez y otros cuyo parentesco no es tan cercano, como Juan Fuero Bayo, Felipe Fuero Jiménez, Pedro Fuero Hortelano, Juan José Fuero Villalba, Silverio Fuero, Isidoro Fuero Vindel, Celedonio Fuero y Teodoro Fuero. ${ }^{16}$ Los lazos matrimoniales, políticos y económicos de la Familia Fuero se explican en la convergencia hacia un ascenso de poder en las elites y la obtención de un mayor influjo social para poder ayudar e insertar, poco a poco, a los familiares de menor edad. ${ }^{17}$ Además, Fermín José contó con una especial relación con su tío Francisco Antonio, quien, desde su mayor posición, rango eclesiástico y autoridad moral, se mostró como un verdadero protector (Benítez Barea, 2001: 57). ${ }^{18}$

Este Francisco Antonio Fuero, que desde 1750 disfrutaba del beneficio curado en Hontanaya (Cuenca), logró definitivamente por oposición el de la villa de Azañón (Guadalajara) en 1758, lo que supuso un momento clave, como demuestra el largo periplo de viajes de familiares que, desde su pueblo natal, se iban a producir con frecuencia, comenzando el año siguiente, con la confirmación de Fermín José: 
El Ilustrísimo Señor José Andrés Caño Obispo de Aradén auxiliar de Sigüenza con licencia del Ilustrísimo Señor Don José Florez Ossorio Obispo de Cuenca hizo confirmación en esta villa de Azañón en el día tres del mes de julio de mil setecientos y cincuenta y nueve, y confirmó las personas siguientes siendo padrino de los varones Isidro del Val y de las niñas y demás mujeres Maria [sic] Vera ambos vecinos de esta dicha Villa. Fermín José hijo de Vicente Fuero y de Manuela Gómez vecinos y naturales de la villa de Cañizares. [Al margen se puede leer una nota] Fermín José [roto] es deán [roto] Santa Iglesia [O]axaca. ${ }^{19}$

De esta forma, y por el fuerte lazo familiar, es indiscutible que debió dirigirse o ser orientado hacia unos estudios que le permitieran alcanzar la universidad e ingresar en la carrera eclesiástica. Los análisis del panorama dieciochesco han revelado que era habitual, y un objetivo muy usual, intentar la pertenencia al estamento clerical, lo que solía suponer la consecución de una serie de privilegios o prerrogativas, teniendo en cuenta que "la Iglesia del XVIII (...) continuaba siendo una institución rica y poderosa, en una nación donde la práctica religiosa estaba profundamente arraigada y era exuberante en su diversidad" (Callaghan, 1989: 12) ${ }^{20}$ Esto determinó, sin embargo, un exceso de aspirantes escasa o nulamente preparados, que no iban a pasar de los estudios más básicos y una sencilla capellanía (Morgado García, 2000: 29). ${ }^{21}$ Su tío Francisco Antonio, quien había nacido en 1723, ya tuvo que afrontar estos primeros años y aprender los rudimentos o primeros estudios del latín, la moral y la gramática, muy probablemente de la mano de algún presbítero o teniente de cura de la propia villa de Cañizares, teniendo en cuenta que el ámbito rural, de principios del siglo XVIII, estaba inmerso dentro de un panorama sacralizado en el que los niños aprendían las letras con ejemplos de contenido profundamente religioso. Pero Fermín José, de quien en su madurez se comentaban sus cualidades y buena preparación, tuvo siempre al lado la grandísima figura de su tío: "Fermín José Fuero (...) el cual es sobrino de dicho cura, y se educó y crió en esta villa de Azañón, y ambos son naturales de la villa de Cañizares". ${ }^{22}$ A partir de aquí, debió poner la vista en la obtención de unos estudios universitarios, por lo que las elecciones eran la universidad de Valencia, la San Antonio Porta Coeli en Sigüenza, o Alcalá de Henares, sabiéndose esta última como una muy buena opción.

Consecuentemente, en 1763 lo encontramos en el Colegio de San Ambrosio, según la Administración de Colegiales, ${ }^{23}$ mientras retoma la serie de visitas a su tío en Azañón. Así, el 30 de marzo, actuó como padrino de José Victorino Humana, ${ }^{24}$ para el 24 de junio serlo compadre de pila, junto con su hermana Teresa Fuero, de Juan Basilio Fernández. ${ }^{25}$ Repetiría con Teresa, pero como padrinos, el dos de agosto de 1764, de Ana María Gallego. ${ }^{26}$ En enero de 1768 escribió:

Don Fermín José Fuero, bachiller en sagrados cánones, cursante de ellos por la Universidad de Alcalá de Henares, natural de la villa de Cañizares de esta diócesis, puesto a los pies de Vuestra Señoría Ilustrísima, con la debida sumisión dice que por su Tribunal de Justicia se le ha adjudicado la capellanía colativa que en la Parroquial de esta última fundaron Juan y Ana Gómez con reserva de la colación para cuando se halle tonsurado, y a este efecto señalado tiempo por lo cual y deseos de lograrla, suplica a Vuestra Señoría Ilustrísima se digne admitirle a dicha prima tonsura (...). ${ }^{27}$

Esto nos indica:

1.- Que estaba cursando los estudios universitarios de cánones, lo que queda demostrado aún más con la ejecución de las averiguaciones y pruebas de limpieza, en febrero del mismo año, que son del tenor siguiente: 
En dicha villa de Cañizares en once días de dicho mes y año pareciéndome estaba suficientemente probada la calidad y limpieza de nuestro opositor y demás sus ascendientes por lo que resulta de las deposiciones de los que dejan dicho inscripto y por los que han dispuesto in voce determine pasar a la Iglesia Parroquial de esta villa para copiar las partidas de bautismos y casamientos que respectivamente en dicha Parroquia estén y conduzcan a esta diligencia, lo que puse en ejecución, de que doy fe. ${ }^{28}$

El resultado final fue la obtención del Grado de Doctor en Cánones por esta Universidad de Alcalá de Henares (Flores). ${ }^{29}$

2.- Que comenzaba su entrada en la carrera eclesiástica, con la solicitud de admisión al grado de corona, justificando además que poseía un apoyo económico y familiar, en la forma de la capellanía colativa que había sido fundada por dos familiares suyos, y que había quedado vacante por renuncia de su tío, Francisco Antonio Fuero.

Y un mes más tarde se contestaba: "Cañizares reverenda para evangelio. En cinco de dicho mes de febrero se despacharon reverendas para tonsura a favor de Fermín José Fuero natural de la villa de Cañizares hijo legítimo de Vicente Fuero Martínez y Manuela Gómez Azañón". 30

El continuado tránsito desde Cañizares a Azañón se plasmó en un tremendo suceso: el fallecimiento de Manuela Gómez Azañón, madre de Fermín y hermana de F. Antonio, el cuatro de octubre de 1769. Enterrada "en una sepultura del banco segundo con diáconos, misa de cuerpo presente y oficio de tres lecciones", había ya otorgado testamento, cuyo resumen recoge al completo el núcleo familiar más cercano, ya que les había nombrado herederos "a sus seis hijos Don Fermín José Fuero colegial de San Clemente de la Universidad de Alcalá, Teresa, Manuel, Jacinto, Manuela y Juan Nepomuceno Fuero. Y nombré por sus albaceas a Juan Fuero su suegro y a sus tres hijos Don Francisco Antonio comisario del Santo Oficio, cura de esta villa, Vicente su marido y Juan su Cuñado". ${ }^{31}$

El infausto destino quiso que sólo cinco años más tarde, el 18 de diciembre de 1774, fuera su hermana, Manuela Fuero Gómez, quien falleciera "habiendo caído enferma de viruelas".

A partir de este momento, con todo, se puede señalar que estaba culminando el trabajo que su tío había venido desarrollando desde su llegada en 1758: la difusión de la doctrina y de la religiosidad que emanaba de la propia institución parroquial: el Ilustrísimo Señor Don Isidro Carvajal y Lancaster, Obispo de Cuenca, estando de visita en 1770, concedió 40 días de indulgencia rezando una salve o ave maría, delante de cada una de las imágenes de María Santísima que se veneraban en la parroquia, como aceptación de petición formulada por Francisco Antonio.

Y es que Azañón había pasado de ser una villa de tercera, a ir adquiriendo un peso específico dentro de la propia diócesis, motivo éste por el que sus paisanos deseaban acudir a recibir, directamente de sus manos, los sacramentos y su disposición de cumplir con su deber espiritual y de formación, cuestión que iba a mantenerse con gran fuerza, como se desprende en el momento de abandonar Azañón: "En 2 de diciembre de 1795 tomó posesión de este curato el Doctor Don Juan Carnicero, Rector y Catedrático de Teología de la Universidad de Sigüenza”.

\section{Datos paralelos a su etapa novohispana}

Esta década iba a ser testigo de su marcha a tierras mexicanas, y antes presenció varios hechos que se fueron sucediendo en tierras muy bien conocidas por él.

Si en el tiempo cercano a su llegada, y según la denominación diversa de las fuentes, ocupó los cargos de Fiscal del Arzobispado de México ${ }^{32}$ o Juez de Testamentos y Obras Pías en la Audiencia Arzobispal ${ }^{33}$ 
o "Provisor de indígenas (juez eclesiástico) en la Curia de México y Abogado de la Audiencia" (Aubry, 1990: 21), ${ }^{34}$ el año 1775 supuso el de Rector de su Universidad, para al año siguiente alcanzar el de Canónigo Doctoral de la Colegiata de Nuestra Señora de Guadalupe.

Corriendo el 13 de junio de 1777, su tío manifestó al Señor Obispo de Cuenca que tenía "determinado construir una capilla en esta dicha Parroquial a sus propias expensas y las de su sobrino el Doctor Don Fermín José Fuero Canónigo Doctoral de la Real Colegiata de Nuestra Señora de Guadalupe de México, para colocar en ella una imagen de Maria Santísima con el título de Dolores". Si la devoción que emana de las cartas de ambos es indudable, la intención de construir la capilla no lo es menos, cuanto que contribuía, además de motivos de conservación y recuperación de "una puerta tapiada con arco de sillería" a "los vivos deseos que manifiestan todos estos vecinos de que tenga efecto esta obra como destinada al culto, y veneración de María Santísima". ${ }^{35}$ Afortunadamente, el cuatro de julio del mismo año obtuvieron el "permiso y licencia" y las obras se prolongaron hasta octubre de 1780.

Sin embargo, este período se tornó nuevamente en la tristeza para ambos, ya que el primero de noviembre de 1779, "falleció Doña María Isabel Juliana Fuero Colegiala que fue del Colegio de Nuestra Señora de Belén de la villa de Cifuentes y natural de la villa de Cañizares". En consecuencia, se trataba de la prima hermana de Fermín José y, por tanto, otro miembro familiar protegido e insertado en las filas eclesiásticas, a cuyo

solemne entierro con oficio de nueve lecciones (...) concurrieron los señores curas de Trillo y de Viana, Don Narciso Carrascoso Racionero de la Santa Iglesia de Sigüenza, Don Sebastián Martínez teniente de cura del lugar de Morillejo anejo [sic]de esta, Fray Miguel Mingo Religioso Predicador del Orden de San Francisco de la Regular observancia, y el dicho Fray Thomas [sic] Pérez cuyo entierro se hizo por la tarde del día dos y en el siguiente a la solemnidad de la misa y oficios asistieron los monjes del Monasterio de Óbila [y] por haber sido la señora difunta hermana de la Orden tercera de San Francisco y pedido se le enterrase con santo ábito, se le puso uno de Religiosa del convento de Belén de monjas franciscanas de la villa de Cifuentes que por lo mucho que la amaban le enviaron dicho ábito sin ejemplar. ${ }^{36}$

Posteriormente, y en relación con esta serie de sucesos familiares, el tío, en representación y sentimiento conjunto, expresó:

En el día 21 de diciembre de 1781 se trasladaron los cadáveres de mi cuñada Manuela Gómez y el de su hija y mi sobrina Manuela Fuero al sepulcro de la capilla que está al lado del evangelio, ambos juntos metidos dentro de una misma caja: y en el mismo día fue trasladado a la misma capilla en el sepulcro de el [sic] lado de la epístola el cadáver de mi amada sobrina Doña Maria Isabel Juliana Fuero hija de mi hermano Juan Fuero, y de su legítima mujer Margarita Gómez, y para que conste lo firmo yo el cura. ${ }^{37}$

Fermín José Fuero, aunque alejado de un núcleo familiar extenso y verdaderamente unido, no decayó, sino que este acontecimiento más bien debió suponer un alto estímulo para la continuación de su ascenso dentro de la carrera eclesiástica, "por brillantes apoyos, pero también por méritos, porque, pese a promociones del propio Rey, gana sus plazas con concursos de oposición". Por este motivo, y porque estaba "agotado a los 37 años, decide rehacer su salud en su patria española", aunque "no dilató más de 100 días", y a cuya vuelta en la fragata Santa Rosalía en diciembre del mismo año, "no deja de ascender en Oaxaca, en donde compra casas y haciendas".

Esta afirmación acerca de la acumulación de posesiones se ha debido fundar sobre tres expedientes del Archivo Episcopal, en los que se recoge lo relativo 
al juicio de expolios, el cual se aplicaba para evitar la corrupción del clero catedralicio, y se comenzaba con motivo del fallecimiento de cada Obispo para que, en caso de pérdida de bienes, éstos se revirtieran nuevamente a la catedral. En este caso se confeccionó para juzgar la actuación de Fermín Fuero y dio lugar a una larga discusión y a una problemática posterior en la que se verían envueltos varios miembros eclesiásticos, incluido su propio hermano Juan Nepomuceno Indalecio Fuero, como Arcediano, lo que debió resultar "en ganancia de canónigos" (Aubry, 1990: 21-22). ${ }^{38}$

No puedo dejar de apuntar unos datos significativos y que enlazan con esa personalidad y dedicación de Fermín: con anterioridad al viaje a España en 1784, regaló tres piezas (dos con data exacta). La primera, junto con su tío, una pieza para la capilla de Nuestra Señora de los Dolores, parroquial de Azañón: 'Un cáliz con su patena de exquisita hechura todo de plata, y dorada la copa por dentro y fuera, con una inscripción en el pie en que se advierte que después de los días de los fundadores el cura de esta parroquial y de su sobrino el Doctor Don Fermín José Fuero, queda dicho cáliz para el uso de la capilla. Se conserva el cáliz dentro de una caja forrada por dentro y fuera", ${ }^{39}$ que según nota añadida al margen se llevó Francisco Antonio, para ser devuelta en 1802, una vez muertos ambos. Afortunadamente, hoy día sigue en Azañón, es empleada con total normalidad y sus vecinos pueden admirar su belleza y sencillez, en cuyo pie se puede leer: "Sacello sept. dolorum B.V. Mariae in parroqviali de Azañon postobitum fundatorum anno 1784".

La segunda, sin nota manuscrita, remite a la parroquial de Santiago Apóstol de Cañizares, donde se conserva una custodia, igualmente en plata y con una inscripción al pie que reza: "A devoción del señor Doctor Don Fermín José Fuero natural de esta villa de Cañizares Canónigo Doctoral de Nuestra Señora de Guadalupe en México, juez ordinario de testamentos y obras pías año 1784". Y por último, existe la nota escrita de la comisión diocesana para el patrimonio artístico y documental de Cuenca, de diciembre de 1979, $\mathrm{n}^{\mathrm{o}} 661,{ }^{40}$ sobre un cuadro de plata, repujado el marco y el cuadro, dedicado a la Virgen de Guadalupe, regalado por el mismo Fermín José Fuero, según las fuentes orales, y cuyo paradero, desafortunadamente, es desconocido.

Estas tres piezas, que respondieron a la ferviente "devoción" de Fermín por su pueblo natal, deben de ser desligadas de los sucesos ya mencionados. Aún más cuanto que fue su núcleo familiar, una pieza clave de las elites locales, con una serie de lazos políticos, económicos y eclesiásticos, demostrables ya desde la obtención de la capellanía colativa que había sido fundada por dos familiares, Juan y Ana Gómez, por un valor de 19,575 reales de vellón, hecha agregación posterior de 1,790 reales que "rentan anualmente más de cien", disfrutada por su tío Francisco Antonio, luego por Fermín y ganada después por Cesáreo Fuero, y que le habían conferido unos recursos y apoyos suficientes para pasar a las Indias. ${ }^{41}$

Fue para 1791 cuando alcanzó el puesto de "Deán de la Santa Iglesia Catedral de Oaxaca en Indias", ${ }^{2}$ según escribió su tío siendo ya canónigo de la de Cuenca, un hito significativo, porque ponía fin a una larga relación con Azañón y con toda una serie de vecinos y familiares que, movidos por la religiosidad, no habían cesado de viajar y buscar el cobijo de su tío. Paralelamente desde esta fecha hasta el fallecimiento de Fermín el 14 de junio de 1800 y de Francisco Antonio el cuatro de enero de 1802, la documentación en la que ambos aparecen de forma muy estrecha, se hace ya muy escasa, principalmente porque no se ha localizado documentación personal de los mismos, correspondencia, notarial o cualquier tipología, si bien habría que tener en cuenta la que se conserva en el archivo de la Arquidiócesis de México y en el Archivo Histórico Diocesano de San Cristóbal de Las Casas, para otros temas. Esto, que ha supuesto un verdadero problema, 
podría aportar datos que darían luz a los últimos años de vida de Fermín y, quizás, esclarecer más sobre la problemática en Indias y los juicios de expolios ya mencionados.

Sin embargo, la documentación relativa a las actuaciones de Fermín en Indias, dejando de un lado todo lo relativo a su etapa española, puede apuntar un período dirigido hacia su nombramiento como Vicario de Oaxaca en 1793 y, finalmente, Obispo de Chiapas, "preconizado el 18 de julio de 1795 " y "consagrado en Guatemala el 11 de septiembre del año siguiente".

Caracterizado por sus virtudes, por la difusión de la Ilustración y sus nuevas ideas ${ }^{43}$ y su preocupación por la falta de enseñanza, "promovió la creación de cuatro escuelas en los conventos de Ciudad Real, y se logró establecerlas en las de Santo Domingo, San Francisco y las Concepcionistas", si bien fue motor de la "evangelización de la tribu de los Lacandones, moral y económicamente, llegándose a formar el pueblo de San José de la Gracia Real" (Flores). ${ }^{44}$

Su figura, reconocida dentro del Obispado de Cuenca, y rodeada y acompañada en todo momento de un espíritu familiar y, a la vez, de aspiración y consecución de un cargo eclesiástico significativo, que se tuvo que materializar en Chiapas, merece la recuperación del tiempo que la historiografía le ha mantenido apartado, de la misma forma que el patrimonio documental chiapaneco que lo contiene debe ser apuntalado, reconocido y difundido en mayor consideración:

Nos el Licenciado Don Manuel González de Villa, presbítero abogado de los Reales Consejos y con Real aprobación, Provisor y Vicario general de esta ciudad de Cuenca y su Obispado. A todas y cuales quiera personas de la villa de Cañizares y otras partes. Hacemos saber que por mandamiento del Ilustrísimo Señor Don Fermín José Fuero Obispo que fue de la Ciudad de Chiapa (...). .4 $^{4}$
Notas

${ }^{1}$ Portal de los Archivos Históricos de Chiapas, ArchivoChiapas-Proyectos, "Recuperación del Patrimonio Histórico Documental de Chiapas: el municipio de San Cristóbal", http: / / www.proimmse.unam.mx/archiapas / proy_sclc.html

${ }^{2}$ Flores Ruiz, Eduardo, La Catedral de San Cristóbal de las Casas, Chiapas, 1528-1978, Universidad Autónoma de Chiapas, Área de Humanidades, Tuxtla Gutiérrez, Chiapas, México, 1978, p.109, “24․ Don José Fermín Fuero y Gómez”, p. 109.

3 Priego Sánchez-Morate, Hilario y José Silva Herranz, Diccionario de personajes conquenses (nacidos antes del año 1900, Cuenca: Diputación Provincial de Cuenca, Sección de Publicaciones, 2002, p.143. En la misma página, unas líneas sobre su tío, Francisco Antonio Fuero.

${ }^{4}$ La imposibilidad de facilitar más datos sobre este hermano del señor obispo se debe a que mi investigación para la consecución del Diploma de Estudios Avanzados (DEA), anteriormente conocido como Tesina Doctoral, se centró en el tío de ambos, don Francisco Antonio Fuero, y en menor medida en Fermín José, habiendo mantenido a Juan Nepomuceno como figura secundaria, por el momento.

Respecto a la candidatura como diputado a la Suprema Junta Central, Cortes Españolas y Diputaciones Provinciales, Reino de Guatemala, 1813-1820, véase DYM, Jordana: Ciudad y ciudadanía en Centroamérica: 1809-1821, V Congreso Hispanoamericano de Historia, San Salvador, El Salvador, 20 de julio de 2000, recurso electrónico http:// www.ues.edu.sv/congreso/dym, \%20colonial.pdf.

Para más datos, el motor de búsqueda del Portail du Réseau Amérique Latine, Système d'information documentaire francophone, recurso electrónico http://www.reseauamerique-latine.fr $/$ bdd.php?base $=$ reseaux 2

${ }^{5}$ Hermanastro de Juan y Fermín, por segundas nupcias del padre, Vicente José Fuero Martínez con Teresa López Gómez.

${ }^{6}$ Seminario Conciliar de San Julián de Cuenca, Matrículas, 1787-1789.

${ }^{7}$ Minguella y Arnedo de las Mercedes, Toribio, Historia de la Diócesis de Sigüenza y sus Obispos, Madrid: [s.n.], 1910-913 (Imp. de la "Revista de Arch. Bibl. y Museos"), vol.3, pp. 411-47, fue uno de los primeros en dedicarle unas líneas. Además, véase: Rodríguez de Coro, Francisco, Fabiány Fuero: un ilustrado molinés en Puebla de los Ángeles, Madrid, Biblioteca de Autores 
Cristianos, 1998, donde el autor ha efectuado un estudio completo de este personaje, en todas sus etapas, teniendo que destacar, para el tema que nos interesa, que no ha mencionado relación de parentesco alguna con cualquier otro de los Fuero que se van a tratar, que sin embargo debió de existir, por línea materna: García-Villoslada, Ricardo (dir.), La Iglesia en la España de los siglos ХИІІ у ХИIII, Madrid Edit. Católica, ВАC Mayor, 19, fundamental para entender el contexto y con varias referencias concretas del personaje. Y como adición a la información recopilada por Rodríguez de Coro, debo señalar que en el Archivo Diocesano de Cuenca (ADC), Inquisición, Depósitos, L-332 (1718-1791), se halla la anotación de los gastos derivados de la obtención de las informaciones de Fabián y Fuero, cuyo encabezamiento es el siguiente: "Sacado en $1^{\circ}$ de septiembre de 1764. La parte de Don Francisco Fabián y Fuero, Presbítero Canónigo y Dignidad de la Santa Iglesia Primada de Toledo, natural de Terzaga, depositó para los gastos de sus informaciones en poder de Don Francisco de Larrea, como Depositario interino, setecientos y trece Reales Vellón.... 713 Reales".

Y como recopilación de sus publicaciones, Palau Y Dulcet, Antonio, Manual del librero hispano-americano: inventario bibliográfico de la producción científica y literaria de España y de la América Latina desde la invención de la imprenta hasta nuestros días: con el valor comercial de todos los artículos descritos, Barcelona, Librería Anticuaria, 1923-1927, t.3 (D-G).

Además, ha alcanzado en algunas ocasiones tanta confusión el apellido Fuero, que el mismísimo Emil Hübner, en las Inscriptiones Hisp. Lat, p. 425, escribe al hablar de Ercávica: «Franciscus Antonius Fabian y Fuero, parochus oppidi de Azañón, postea canonicus ecclesiae cathedralis de Cuenca.», habiendo confundido al Obispo de Puebla con el Cura de Azañón y Canónigo de Cuenca, Francisco Antonio Fuero Gómez, tío de Fermín y Juan Nepomuceno.

${ }^{8}$ Los arzobispos de Toledo y la universidad española, exposición del 5 de marzo - 3 de junio de 2002, Iglesia de San Pedro Mártir (Toledo), organizada por la Universidad de CastillaLa Mancha, con la colaboración del Arzobispado de Toledo (et al), coordinación del catálogo, J. Carlos Vizuete Mendoza, Fernando Llamazares Rodríguez, Julio Martín Sánchez, Cuenca, Servicio de Publicaciones de la Universidad de Castilla-La Mancha, 2002, pp. 308-313.
${ }^{9}$ Entre otras cuestiones, la reforma universitaria valenciana, que enfrentará a los tomistas contra los antitomistas y los nombramientos de cargos en la misma, Albiñana Huerta, Salvador, "La enseñanza y la univesidad. Los conflictos escolásticos y el rectorado de Juan Antonio Mayans en la Universidad de Valencia", Congreso Mayans y la Ilustración: Simposio Internacional en el Bicentenario de la muerte de Gregorio Mayans, Valencia-Oliva, 30 de sept. - 2 de oct., Valencia, Ayuntamiento de Oliva, 1981, t. II.

${ }^{10}$ Bas Martín, Nicolás, El cosmógrafo e historiador Juan Bautista Muñoz: (1745-1799), València: Universitat, 2002, p. 53; Mestre Sanchís, Antonio, Historia, fueros y actitudes políticas : Mayans y la historiografía del XVIII, Valencia, Servei de Publicacions de la Universitat de Valéncia, 2000, p. 320 y 410; y para el mencionado enfrentamiento, López, François, Juan Pablo Forner (1756-1797) y la crisis de la conciencia española, traducción de Fernando Villaverde, Salamanca, Junta de Castilla y León, Consejería de Educación y Cultura , 1999, pp. 551-553 y 652; Miguélez, Manuel F., Jansenismo y regalismo en España: (Datos para la historia) Cartas al Sr. Menéndez Pelayo, Valladolid, Luis N. de Gaviria, 1895; La Parra López, Emilio, "Iglesia y grupos políticos en el reinado de Carlos IV", en Hispania Nova, núm. 2 (2001-2002); Lasalde , C., "Dos cartas del príncipe de la Paz", en Revista Contemporánea, año xxiv, octubre 1898, p. 13.

${ }^{11}$ Martínez Ferrer, Luis, La presencia de Santo Tomás de Aquino en la Nueva España: el decreto del III Concilio Mexicano (1585) sobre la Fiesta del Doctor Angélico, http:// www.colmich.edu.mx/relaciones/097/pdf/ Luis $\% 20$ Mart $\%$ EDnez $\% 20$ Ferrer.pdf.

${ }^{12} \mathrm{Al}$ momento de la elaboración del presente artículo, tengo que señalar que la imposibilidad de la consulta de las publicaciones mexicanas en las que se menciona a Fermín Fuero han sido casi nulas, a excepción de los datos de los recursos electrónicos, así como los extractados de obras completas, gracias a la inestimable colaboración de don Sergio Nicolás Gutiérrez Cruz, de la Universidad de Ciencias y Artes de Chiapas (UNICACH).

Para la etapa española no es mejor la situación bibliográfica, debido a la casi total ausencia de obras que traten sobre su vida en cualquier aspecto o, al menos, lo mencionen indirectamente. 
${ }^{13}$ AHN, Universidades y Colegios, leg. 391, nº 13. Nótese que en el índice de colegiales no aparece Fuero, sino que se transcribió por Tuero. 1768.

${ }^{14}$ Martínez Vellisca, David, La Arqueología Clásica española durante el siglo XVIII. La obra de D. Francisco Antonio Fuero (1723-1802), trabajo de investigación inédito para la obtención del mencionado DEA, Departamento de Historia Moderna, bajo la supervisión de D. José Martínez Millán, Universidad Autónoma de Madrid, septiembre de 2003.

${ }^{15}$ Este Pedro fue hermano de Cesario y, por tanto, también hermanastro del Obispo Fermín José y de Juan Nepomuceno.

${ }^{16}$ Para algunos de ellos, Seminario Conciliar de San Julián de Cuenca, Relación alfabética de alumnos del Seminario Conciliar de San Julián, alumnos hasta junio de 1999, p.82, libro de control interno del Seminario, consultado gracias a D. Enrique de la Rica Barriga, siendo Cura Párroco de Cañizares (Cuenca) en 2002/2003; y Matrículas, 1787-1789.

${ }^{17}$ Chacón Jiménez, F., Studia Historica. Edad moderna, 18 (1998), monográfico sobre esta cuestión, a la que se pueden añadir los trabajos de Imízcoz, J.M. (dir), Redes familiares y patronazgo. Aproximación al entramado del País Vasco. Universidad del País Vasco, 2001; Chacón Jiménez, F. (ed)., Familia y sociedad en el Mediterráneo Occidental, Murcia, 1987; y Hernández Franco, J. (ed), Familia y poder. Sistemas de reproducción social en España (siglos XVI-XVIII), Murcia, 1995, que contienen una completa bibliografía sobre el tema.

${ }^{18}$ Benítez Barea, Avelina, El bajo clero rural en el Antiguo Régimen (Medina Sidonia, siglo XVIII), Cádiz, Universidad, Servicio de Publicaciones, 2001, pp. 57 y 58, donde señala que las relaciones intrafamiliares y las solidaridades llegaban a adquirir una gran fuerza, incluso sobrinos que eran ayudados y promocionados por otro familiar que ya era eclesiástico.

${ }^{19}$ ADS (Archivo Diocesano de Sigüenza), Azañón, Bautismos, 1569-1850, libro 3, hoja suelta.

${ }^{20}$ Callaghan, William J., Iglesia, podery sociedad en España, 1750 1874, Madrid, 1989, p. 12.

${ }^{21}$ Morgado García, Arturo, Ser clérigo en la España del Antiguo Régimen, Cádiz, Servicio de Publicaciones, Universidad de Cádiz, 2000, p. 29.
${ }^{22}$ ADs, Libros de fábrica, 1722-1815, tomo $4^{\circ}$.

${ }^{23}$ AHN, Informaciones Genealógicas, Universidades, leg. 946F, Fermín José, 1763, Colegio de San Ambrosio. Años más tarde, su tío Francisco Antonio, escribió que fue "Colegial de San Clemente", desconociendo su fecha. Además, Christophe Belaubre y Rodolfo Hernández Méndez en 'El canónigo Antonio García Redondo y los orígenes de la independencia centroamericana: un acercamiento de su influencia pública a partir del concepto de redes (17801810)", Re-Vista, Instituto de Estudios Históricos, Antropológicos y Arqueológicos, no 2, nov-feb. 2004, pp. 7-22, recurso electrónico http://ress.afehc.apinc.org/ articulos2/fichiers/portada_afehc_articulos4.pdf, apunta que Fermín estudió en Alcalá de Henares, de la misma forma que el Arzobispo Juan Félix de Villegas.

${ }^{24}$ ADS, Azañón, Bautismos, 1569-1850, libro 3, f f .13 rto.

${ }^{25}$ ADs, Azañón, Bautismos, 1569-1850, libro 3, f․ 13 vto.

${ }^{26}$ ADs, Azañón, Bautismos, 1569-1850, libro 3, fo. 16 vto-17 rto.

${ }^{27}$ ADC, Órdenes, leg.648.

${ }^{28}$ AHN, Universidades y Colegios, leg. 391, no 13, fo 2 rto.

${ }^{29}$ Flores, sobre este dato, desconozco la fuente manuscrita.

${ }^{30}$ ADC, Órdenes, Libros, n 75 , 1734-1771, fo .386 rto. Es de suponer que en este libro y siguientes de esta sexta serie se hallarán las demás órdenes de Fermín, si bien su hermano Juan Nepomuceno aparece en septiembre de 1782 para tonsura y en el mismo mes de 1788 para grados y epístola.

${ }^{31}$ ADS, Azañón, Difuntos, 1758-1852, fo .55.

32 ADs, Azañón, Libro de 17 documentos, fo 14 vto - 16 rto, varias anotaciones, rubricadas por su tío.

${ }^{33}$ ADS, Azañón, Libros de fábrica, 1722-1815, tomo $4^{\circ}$.

${ }^{34}$ Aubry, Andrés, Los obispos de Chiapas, Instituto de Asesoría Antropológica para la Región Maya, San Cristóbal de las Casas, Chiapas, 1990, pp. 41-42.

${ }^{35}$ ADS, Azañón, Libro de 17 documentos.

${ }^{36}$ ADS, Azañón, Difuntos, 1758-1852, f 999

${ }^{37}$ ADS, Azañón, Difuntos, 1758-1852, fo.99

${ }^{38}$ ADS, Azañón, Difuntos, 1758-1852, fo .99

${ }^{39}$ ADS, Azañón, Libros de fábrica, 1722-1815, tomo 4 ㅇ $^{\circ} .30$ rto.

${ }^{40}$ Cañizares, Archivo de la Parroquia de Santiago Apóstol, Comisión Diocesana para el Patrimonio Artístico y Documental, 1979 y 1980, varias fichas. 
${ }^{41}$ ADC, Capellanías, leg. 280-9. 1803-1804. En este expediente se recogen la fundación, patronato, oposición y adjudicación de la capellanía, edicto de notificación del opositor Cesáreo Fuero, y otros datos que han servido para recomponer la ausencia de libros sacramentales de la villa de Cañizares.

${ }^{42}$ ADS, Azañón, Libros de fábrica, 1722-1815, tomo 4 , f .30 rto.
${ }^{43}$ Belaubre, Christophe y Hernández Méndez, "El canónigo...".

${ }^{44}$ Flores.

${ }^{45}$ ADC, Capellanías, leg. 280-9 Cuenca, 23 de julio de 1803. Edicto de notificación de citación de opositores que concurran a la vacante de la Capellanía fundada por Juan y Ana Gómez en Cañizares. 